\title{
Multicore Myopathy: Not Always a Benign Entity
}

\author{
Ashfaq Shuaib, Justin M.E. Martin, L. Brent Mitchell and A. Keith W. Brownell
}

\begin{abstract}
Four patients with Multicore Myopathy, a rare morphologically distinct myopathy, are described. Although previously considered to be a non-progressive or only slowly progressive myopathy, progression to significant disability was seen in three of our cases. The association of cardiac disease with Multicore Myopathy has not been previously emphasised. All four patients in this study had a cardiomyopathy, and heart disease was the cause of death in two of the patients. Multicore Myopathy is not always a benign entity. Cardiac involvement, when present, adversely affects prognosis.
\end{abstract}

RÉSUMÉ: La myopathie congénitale à foyers multiples: une entité qui n'est pas toujours bénigne Nous décrivons les cas de 4 patients atteints de myopathie congénitale à foyers multiples, une myopathie rare dont la morphologie est caractéristique. Même si cette myopathie est considérée comme étant non-progressive ou seulement lentement progressive, nous avons observé une progression vers une invalidité importante chez 3 de nos cas. L'association d'une atteinte cardiaque avec la myopathie congénitale à foyers multiples n'a jamais été soulignée antérieurement. Nos 4 patients étaient porteurs d'une cardiomyopathie et l'atteinte cardiaque était la cause du décès dans les 2 cas où l'issue a été fatale. La myopathie congénitale à foyers multiples n'est pas toujours une entité bénigne. La présence d'une atteinte cardiaque en assombrit le pronostic.

Can. J. Neurol. Sci. 1988; 15:10-14

Electrocardiographic abnormalities and cardiac disease have been observed in association with a number of different muscle diseases with the frequency, severity, and characteristics of these abnormalities varying with the type of muscle disease. ${ }^{1.4}$ Although myopathic symptoms usually predominate, cardiac symptoms may bring these patients to medical attention, with the muscle weakness being noticed during examination, ${ }^{2.5 .6}$ or developing later during the course of the disease. ${ }^{7}$

Multicore Myopathy (MCM) was initially described by Engel et al in 1966 and 1971 in two unrelated children ${ }^{8,9}$ Since then, additional case reports have been published. ${ }^{10-24}$ These case reports suggest that $\mathrm{MCM}$ is commonly manifested at an early age and is either non-progressive or only slowly progressive. The muscle weakness is usually most pronounced proximally and there is an associated mild to moderate decrease in muscle bulk. Skeletal deformities, such as kyphoscoliosis, contractures, and clubfoot have occasionally been reported..$^{25}$

The terminology used to describe this entity has varied and includes designations such as multicore disease, ${ }^{9}$ myopathy with multiple minicores, ${ }^{13}$ familial loss of cross striations, ${ }^{18}$ myopathy with minicores, ${ }^{19}$ and minicore myopathy..$^{24}$ We prefer the term multicore myopathy (MCM), which Banker ${ }^{25}$ introduced, to refer to this entity.

Reports of cardiac involvement in MCM are rare. Two patients have been described with congestive cardiac failure secondary to atrial ${ }^{20}$ and ventricular septal defects. ${ }^{8}$ One patient responded well to corrective cardiac surgery. ${ }^{8}$ The second patient died at the time of cardiac catherization. ${ }^{20}$ Autopsy examination showed a patent foramen ovale, a dilated atrium and a markedly dilated right ventricle with focal wall thickening and fibrosis. ${ }^{20}$ Two other reports describe "electrocardiographic" evidence of a cardiomyopathy ${ }^{10}$ and biventricular enlargement. ${ }^{21}$

In this paper, we describe four patients with MCM who demonstrated clinically significant cardiac disease. Furthermore, the myopathic symptoms, that these patients experienced, were much more severe than has been described previously. The myopathic symptoms, in two of these patients (Cases I and 2), have been briefly described in abstract form. ${ }^{22,23}$

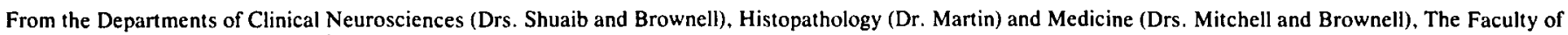
Medicine, University of Calgary, Calgary

Received February 5, 1987. Accepted June 30, 1987

Reprint requests to: A. Keith W. Brownell M.D., Department of Clinical Neurosciences, The University of Calgary, Foothills Hospital, 1403 29th St. N.W., Calgary, Alberta, Canada T2N 2T9 


\section{Case Reports}

\section{Case One}

This 41-year-old female had muscle weakness that dated back as far as she could remember. Initially, the weakness was confined to the muscles of her shoulder girdle but gradually it progressed to involve her neck flexor and pelvic girdle muscles. Her initial examination at age 33, demonstrated mild atrophy of shoulder girdle muscles and mild weakness involving neck flexors, and shoulder and pelvic girdle muscles. Strength in distal muscles was normal. Muscle biopsy indicated MCM (Fig. IA and 3).

Her initial cardiac examination was also carried out at age 33 because of a two year history of gradually progressive dyspnea. Examination showed resting tachycardia, increased jugular venous pressure with sustained hepatojugular reflux, cardiomegaly, and the murmurs of both tricuspid and mitral insufficiency. The clinical diagnosis of congestive cardiomyopathy was confirmed with chest roentgenographic, electrocardiographic, and two dimensional echocardiographic examinations. The patient responded to diuretics and digoxin therapy, and she has shown no further progression of cardiac dysfunction.

Over eight years of follow-up, her proximal weakness has increased in severity and involvement of distal musculature, particularly in her legs, is now evident. Since the age of 39 years, she has required the assistance of a wheelchair.

\section{Case Two}

This patient (the daughter of Case 1) was initially examined at age 15 because of progressive muscle weakness and a vertebral column deformity. Weakness, initially confined to her shoulder girdle muscles, was first noted at age 4 . Shortly afterwards, symmetric leg weakness developed. At the time of presentation, the patient had kyphoscoliosis and a waddling gait. Mild to moderate weakness was noted in facial, shoulder,

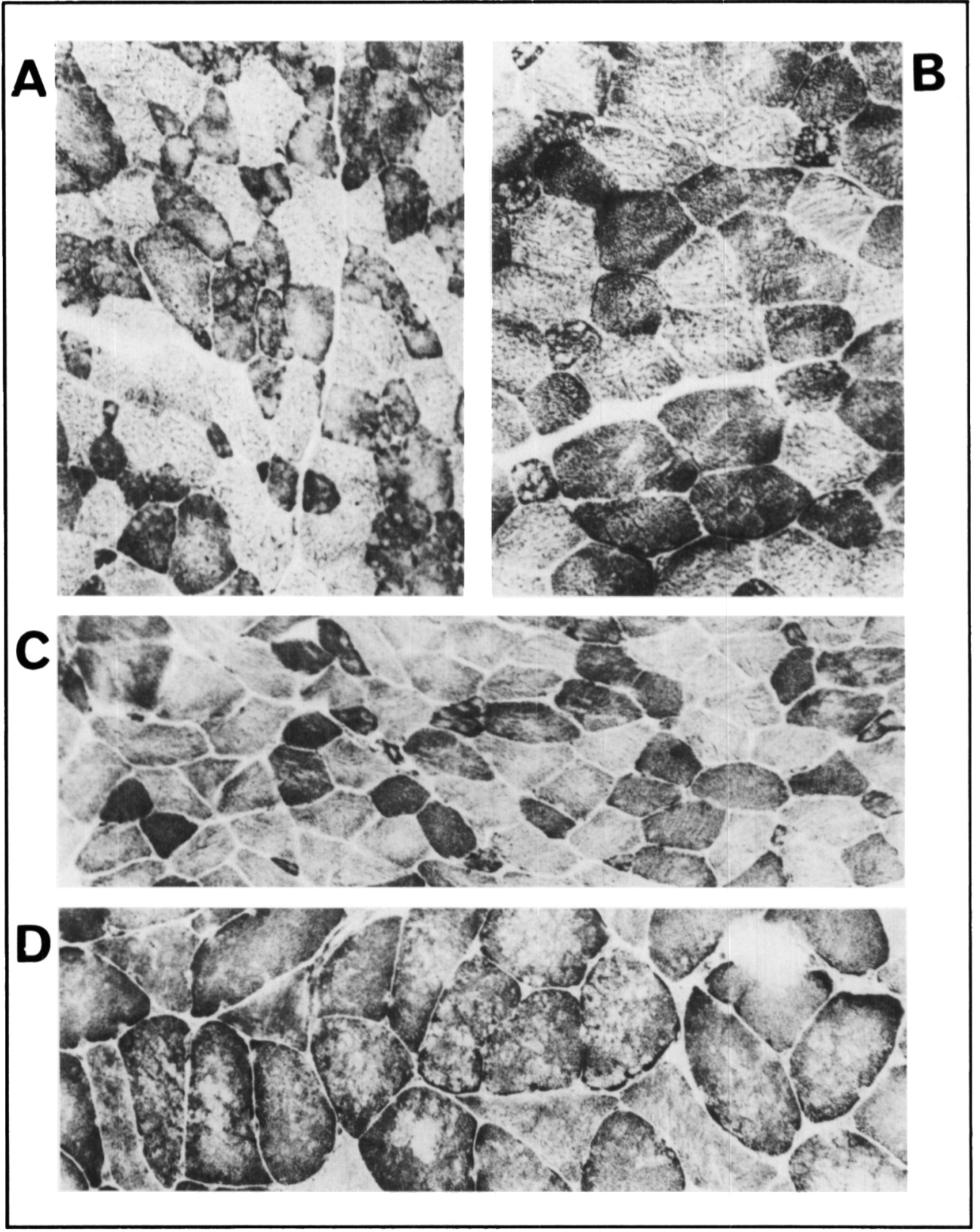

Figure I (A-D) - All photomicrographsarefrom frozen sections of muscle reacted for nicotinamide adenine dinucleotide dehydrogenase. Multiple, small, fairly well demarcated areas of reduced or absent reaction product are seen in individual muscle fibers in each biopsy. (XI25) 


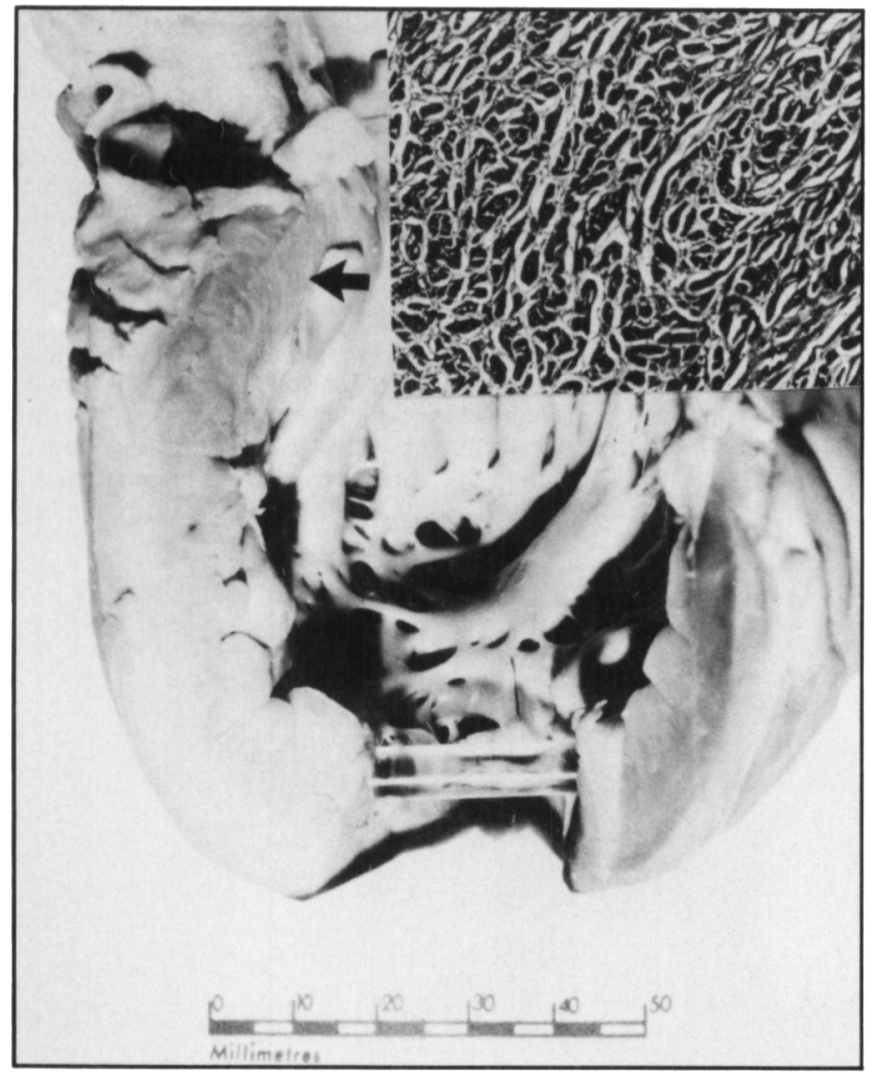

Figure 2 - The left ventricular myocardium is markedly hypertrophied and contains prominent trabeculae. The interventricular septum has a grossly whorled ("watered silk") appearance (arrow). Inset: Disorderly and hypertrophied myocardial fibers are separated by fibrotic strands. (Trichrome $X 200)$

and pelvic girdle muscles. Her distal muscles were also mildly weak. Tendon reflexes were absent at the elbows and knees. The rest of her examination, including cardiac examination, was normal. Clinically, she was thought to have facioscapulohumeral muscular dystrophy. However, MCM was evident on the muscle biopsy (Fig. 1B and 4).

At age 17 her chest $X$-ray showed cardiomegaly, and her electrocardiogram revealed left ventricular hypertrophy. A clinical diagnosis of hypertrophic cardiomyopathy was made.

A Harrington rod instrumentation was also carried out at age 17 for treatment of her progressive scoliosis. Later the same year, pulmonary edema was precipitated by a respiratory tract infection.

During the next two years, her cardiovascular status periodically decompensated despite treatment with diuretics and digoxin. Also, muscle weakness progressed to the point where she required the assistance of a wheelchair.

At age 19, an episode of severe congestive heart failure, complicated by sepsis and disseminated intravascular coagulation, led to her death. At autopsy, her heart showed findings diagnostic of hypertrophic cardiomyopathy.

\section{Case Three}

The diagnosis of hypertrophic cardiomyopathy was made in this patient (daughter of Case 1) at age 8 years, after she complained of dyspnea on exertion. There was no history of muscle weakness.

At age 16, she had an out-of-hospital cardiac arrest and resuscitation was unsuccessful

At autopsy, gross examination of her central nervous system showed no abnormalities. Muscle taken from her pectoralis major muscle revealed MCM (Fig. IC). Her heart weighed 450 gms. There was hypertrophy, of both atria and ventricles, which was most prominent in the interventricular septum. Microscopic examination of her myocardium revealed short, thickened muscle fibres arranged in a disorderly manner with bizzare and pleomorphic nuclei characteristic of hypertrophic cardiomyopathy. Abundant fibrous tissue was also noted. Some of these features are illustrated in Figure 2.

\section{Case Four}

This 61-year-old male presented, at age 51, with dyspnea on exertion and chest pain. Physical examination was consistent with biventricular cardiac failure. Chest X-ray, two dimensional echocardiography, and cardiac catherization revealed congestive cardiomyopathy with normal coronary arteries. Over the years he has required numerous hospital admissions for the treatment of heart failure and malignant ventricular arrythmias.

Although he had noticed muscle weakness since early adulthood, no specific myopathic diagnosis had ever been made. Muscle weakness and wasting in the shoulder region was initially attributed to cervical radiculopathy secondary to degenerative cervical spine disease. However, the weakness spread, very gradually, to involve both arms and legs. Over the years, he had also noted some decrease in muscle bulk, especially in the shoulder regions. His brother had died from "cardiac problems" at age 45 .

His most recent cardiovascular examination showed advanced biventricular failure with increased jugular venous pressure, sustained hepatojugular reflux, laterally displaced apical impulse, a $S_{3}$ and $S_{4}$, and the murmur of mitral insufficiency. Muscular examination revealed a mild degree of muscle wasting of his shoulder and pelvic girdle muscles, and his neck muscles were very weak (extensors more than flexors), as were his shoulder and pelvic girdle muscles. In addition, there was mild weakness in the elbow flexors. Tendon reflexes were normal. A muscle biopsy taken from his right deltoid muscle indicated MCM (Fig. 1D)

\section{Discussion}

If the diagnosis of MCM is made in an infant or child, the literature suggests that the degree of weakness present will be mild, and the disease will usually be non-progressive and follow a relatively benign course..$^{9,11,12,13} \mathrm{~A}$ recently published case report, involving an infant, is the first account in the literature of MCM producing severe weakness. ${ }^{20}$ Because reports of MCM in adults are infrequent, it is difficult to know whether or not the course of the disease will be similar to that seen in children. One report suggested non-progression or improvement with time. ${ }^{11}$ However, other reports suggested a progressive course. ${ }^{14,25}$ The weakness definitely progressed in three of our patients, with two patients eventually requiring the assistance of wheelchairs. Most reports describe the weakness as

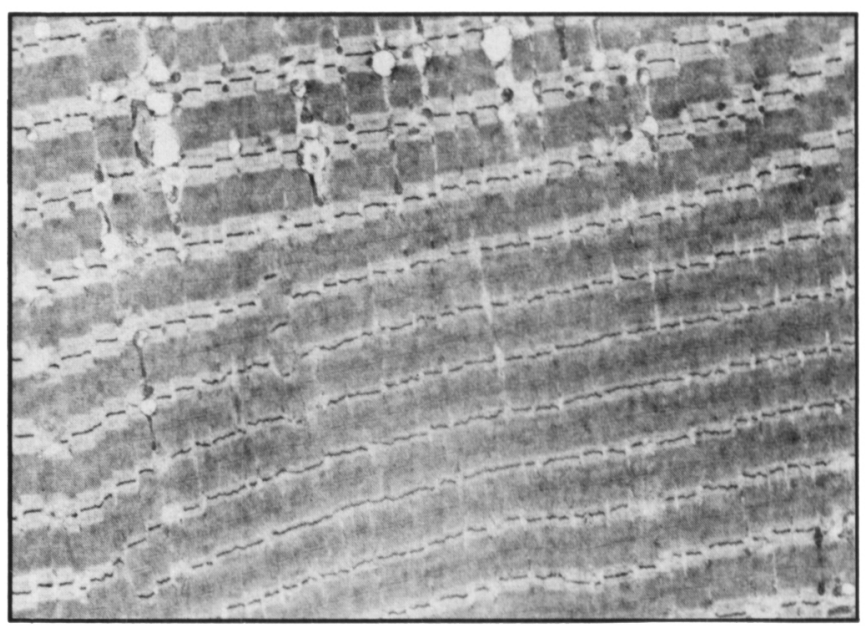

Figure 3 - Electronmicrograph showing a typical corelesion. Note the absence of mitochondria and the normal contractile apparatus. The core is surrounded by normal muscle on two sides. $(X 6,000)$ 


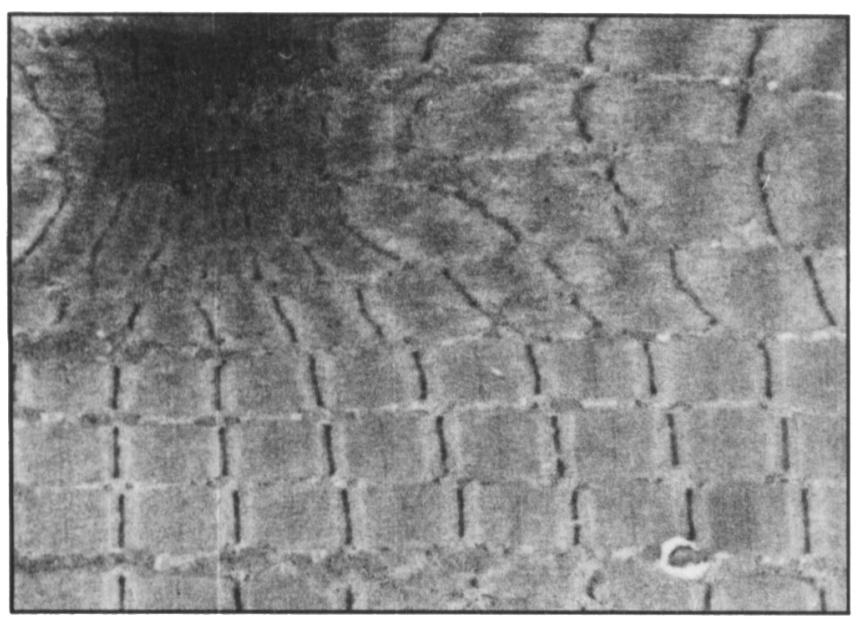

Figure 4-Electronmicrograph showing another core. In addition to demonstrating the absence of mitochondria within the core, myofibrillar architecture is disorganized. $(X 12,000)$

proximal, affecting the facial, shoulder and pelvic girdle muscles. However, in some reports no weakness was found on examination. ${ }^{11,17}$ The distribution of weakness in our cases was similar to that described in previous reports. Improvement in strength with time, as reported in some studies, ${ }^{11,13,21}$ was not seen in any of our cases. Although areflexia has been noted, ${ }^{14,15,21}$

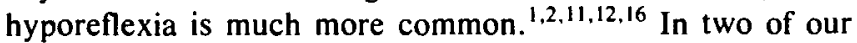
patients the tendon reflexes were normal. The third patient showed focal absence of some reflexes while the reflex status of the fourth patient is unknown.

A number of musculoskeletal defects have been associated with MCM including kyphoscoliosis, ${ }^{13,17}$ high arched palate, ${ }^{15,17,21}$ polythelia, ${ }^{13}$ hemifacial assymetry, ${ }^{12}$ pes cavus ${ }^{17,25}$ and dolicomorphic habitus and dolicocephaly. ${ }^{24}$

Kyphoscoliosis can be progressive, resulting in recurrent pulmonary infections, ${ }^{17}$ and may at times require surgical correction. ${ }^{17}$ Surgical correction was required in our patient with kyphoscloiosis.

Muscle weakness, attributed to cardiac cachexia, may be seen as a non-specific finding in many patients with advanced cardiac failure ${ }^{26}$ This type of weakness should be differentiated from weakness secondary to an underlying myopathy. The differentiation may be quite difficult when cardiac disease precedes the onset of muscle weakness.

Although cardiac involvement in MCM has been reported, our case reports are the first to systematically assess the presentation, response to treatment and prognosis when cardiac involvement occurs in MCM. Hypertrophic cardiomyopathy was seen in two patients. The cardiac symptoms experienced by these two patients were similar to those experienced by patients with hypertrophic cardiomyopathy without muscle disease ${ }^{27}$ The diagnosis of MCM, in one of these patients, was made at autopsy (Case 2). The other patient (Case 3), had presented with symptoms of muscle weakness, with heart failure and cardiac arrythmias developing within one year. She died two years following the onset of symptoms of her hypertrophic cardiomyopathy and four years following the diagnosis of MCM. The two patients (Cases 1 and 4) with dilated, congestive cardiomyopathy have survived. In Case 1, the cardiomyopathy is asymptomatic with supportive treatment after eight years of follow-up. Case 4 is still alive, 11 years after the onset of cardiac symptoms, but is disabled by congestive heart failure and malignant cardiac arrythmias, despite maximal medical therapy.

MCM is diagnosed when a muscle biopsy demonstrates multiple small cores within muscle fibers as the most prominent pathological change. Using light microscopy, the cores can be demonstrated best by oxidative enzyme histochemistry or polarized light. Transmission electron microscopy demonstrates the changes in the greatest degree of detail.

Our patients, although fulfilling the pathological criteria for the diagnosis of MCM, are quite different clinically from most of the other cases that have been described up to this time. Why might this be? First, since only a very small number of patients with this myopathy have been reported thus far, it should not be surprising that the clinical spectrum of the disease was much broader than was originally described. This has been a common observation with most diseases, following their initial description. Secondly, it is recognized that multicores are not pathognomonic for MCM since they can be seen in muscle biopsies from conditions as diverse as malignant hyperthermia, muscular dystrophy, inflammatory myopathies, denervation atrophy, endocrinopathies, emetine myopathy and glucocortocoid treated rats. ${ }^{25}$ It may be that if a more specific marker for MCM is discovered, it will be appreciated that the patients who carry the diagnosis of MCM may turn out to be a very heterogenous group that will have to be further subdivided.

The association of significant cardiac disease and MCM in these four cases suggests that all patients with MCM should be evaluated for cardiomyopathy at presentation and on follow-up. Cardiac involvement may adversely affect the prognosis in this, otherwise, relatively benign myopathy. Finally, it is important to note that the muscle weakness itself may be progressive, resulting in significant limitation of muscular function.

\section{REFERENCES}

1. Perloff JK. Cardiac involvement in neuromyopathic diseases. In: Burch GE ed. Cardiomyopathy. Philadelphia: FA Davis 1972; 334-343. (Brest AN, ed. Cardiovascular Clinics, Vol 4).

2. Griggs RC. Hypertrophy and cardiac involvement in neuromuscular diseases. Circ Res 1974; 35 (Supp 11): 145-151.

3. Perloff JK. Cardiomyopathy associated with heridofamilial neuromyopathic diseases. Mod Conc Cardiovasc Dis 1971; 40: 23-26.

4. Welsh JD, Lynn TN Jr, Hasse AR. Cardiac findings in 63 patients with muscular dystrophy. Arch Int Med 1963; 112: 199-206.

5. Merlini L, Granata C, Dominici P et al. Emery-Dreifuss muscular dystrophy. Report of five cases in a family and review of the literature. Muscle Nerve 1986: 481-485.

6. Mawatari S, Katayama K. Scapulomuscular atrophy with cardiomyopathy. Arch Neurol 1973; 28: 55-59.

7. Norris FH, Moss AJ, Yu PN. On the possibility that a type of human muscular dystrophy commences in the myocardium. Ann NY Acad Sci 1967; 138: 342-355.

8. Engel AG, Gomez MR. Congenital myopathy associated with focal degeneration of muscle fibres. Trans Am Neurol Assn 1966;891: $222-223$.

9. Engel AG, Gomez MR, Groover RV. Multicore disease: A recently recognized congenital myopathy associated with multifocal degeneration of muscle fibres. Mayo Clin Proc 1971; 46: 666-681.

10. Bender AN. Congenital myopathies. In: Ringle $S$ ed. Diseases of Muscle, part 2. Amsterdam: North-Holland Publishing Co 1979, 1-26. (Vinken PJ, Bruyn GW eds: Handbook of Clinical Neurology, vol 41).

11. Vanneste JA: Autosomal dominant multicore disease. J Neurol Neurosurg Psychiatry 1976; 45: 602-606. 
12. Heffner R, Cohen M, Duffner P et al. Multicore disease in twins. J Neurol Neurosurg Psychiatry 1976; 39: 602-606.

13. Ricoy JR, Cabello A, Goizveta G. Myopathy with multiple minicores: A report of two siblings. J Neurol Sci 1980; 48: 81-92.

14. Bonnette H, Roelofs R, Olson WH. Multicore disease: Report of a case in middle age. Neurology (Minneap) 1974; 24: 1039-1044.

15. Swash M, Schwartz MS: Familial multicore disease with focal loss of cross striations and ophthalmoplegia. J Neurol Sci 1981; 52: 1- 10.

16. Taratuto AL, Sfaello ZM, Rezzonico C et al. Multicore dissase: Report of a case with lack of fiber type differentiation. Neuropadiatrie 1978; 9: 285-297.

17. Fitzsimons RB, Tyer HDD. A study of myopathy presenting as idiopathic scoliosis. J Neurol Sci 1980; 46: 33-48.

18. VanWijngaarden GK, Bethlem J, Diugemans KP et al. Familial loss of cross striations. J Neurol 1977; 216: 163-172.

19. Lake BD, Cavanaugh N, Wilson J. Myopathy with minicores in siblings. Neuropath Appl Neurobiol 1977; 3: 159-168.
20. Koch BM, Bertorini TE, Eng GD et al. Severe multicore disease associated with reaction to anesthesia. Arch Neurol 1985; 42: 1204-1206.

21. Isaacs H, Badenhorst M. Multicore disease. S Afr Med J 1980; 57: 543-546.

22. Brownell $A K W$. Familial multicore disease [Abstract]. Ann Neurol 1978; 6: 155.

23. Brownell AKW. Familial multicore disease [Abstract]. Trans Am Neurol Assn 1979; 104: 130-133.

24. Paljarvi L, Kalimo $\mathrm{H}$, Lang $\mathrm{H}$ et al. Minicore myopathy with dominant inheritance. J Neurol Sci 1987; 77: 11-22.

25. Banker BQ. The congenital myopathies. In: Engel AG, Banker BQ eds. Myology. New York: McGraw-Hill 1986: 1527-1584.

26. Pittman JG, Cohen P. The pathogenesis of cardiac cachexia. New Engl J Med 1964; 271: 403-409, 453-460.

27. Wegner WK, Goodwin JF, Roberts WC. Cardiomyopathy and myocardinal involvement in systemic diseases. In: Hurst JW ed. The Heart. 6th ed. NY: McGraw-Hill 1986, 1181-1248. 